\title{
Pendidikan Kesehatan Mobilisasi Dini Pasca Bersalin
}

\author{
Isnaeni Rofiqoch, Purwati, Wulan Margiana \\ Email: neni.rofiqoch@gmail.com \\ Program Studi Kebidanan DIII, Fakultas Ilmu Kesehatan, Universitas Muhammadiyah Purwokerto, \\ Indonesia \\ Jl. Letjen Soepardjo Roestam Km 7 PO BOX 229 Purwokerto 53181 \\ Telp. (0281) 6844252, Fax.(0281) 6844253
}

\begin{abstract}
Abstrak
Pendidikan kesehatan merupakan proses pemberian pengetahuan dan proses dalam penyadaran masyarakat tentang pentingnya suatu kesehatan. Pendidikan kesehatan tentang mobilisasi dini bagi ibu postpartum dapat memberikan pengetahuan lebih tentang kesehatan kepada ibu ataupun kepada keluarga agar dapat mengatasi masalah dan mempercepat proses penyembuhan pasca bersalin. Hal ini di karena tahap postpartum merupakan salah satu tahap yang rentan terhadap kejadian perdarahan dan infeksi pada ibu, dan menjadi penyebab terjadinya kematian pada ibu. Metode dalam pelaksanaan IbM dilakuan dengan metode learning by doing (belajar dengan mempraktekkan) dengan teknik transfer ilmu dilakukan melalui penyuluhan, pelatihan dan praktek skill. Pada pelaksanaan pemberian pendidikan kesehatan tentang mobilisasi dini pasca bersalin terdapat peningkatan pengetahuan sebelum dan setelah dilakukan pemberian pendidikan kesehatan tentang mobilisasi dini pasca bersalin. Pemberian pendidikan kesehatan tentang mobilisasi dini pasca bersalin diberiakan sedini mungkin dengan harapan, ibu yang post partum dapat langsung mempraktikan dan membantu penyembuhan luka uterus dan jalan lahir pasca bersalin.
\end{abstract}

Kata Kunci: mobilisasi; pendidikan kesehatan; nifas.

\begin{abstract}
Health education is a process of providing knowledge and a process in public awareness of the importance of health. Health education on early mobilization for postpartum mothers can provide more knowledge about health to mothers or their families in order to overcome problems and accelerate the postpartum healing process. This is because the postpartum stage is one of the stages that is susceptible to bleeding and infection in the mother, and a cause of death in the mother. The method in implementing IbM is carried out by the method of learning by doing (learning by doing) with the transfer of knowledge through counseling, training and skill practice. In the implementation of providing health education about early mobilization after childbirth there is an increase in knowledge before and after providing health education about early mobilization after childbirth. Providing health education about early postpartum mobilization is carried out as early as possible, with the hope that post-partum mothers can immediately practice and help heal uterine wounds and postpartum birth canals.
\end{abstract}

Keywords: mobilization; health education; childbirth.

\section{Pendahuluan}

Promosi

merupakan suatu revitalisasi

pendidikan kesehatan, dimana konsep promosi kesehatan bukan hanya proses pemberian pengetahuan akan tetapi juga proses dalam penyadaran masyarakat akan pentingnya suatu kesehatan. Pendidikan Kesehatan (PENKES) dan Konseling sangat penting untuk menambah pengetahuan bagi ibu, terutama ibu-ibu muda yang memang baru pertama kali hamil, bersalin, dan nifas. Hal ini dikarenakan ibu-ibu tersebut masih belum memiliki 
pengalaman yang dapat di jadikan contoh. Sehingga dengan adanya pemberian Penkes atau konseling sangat membantu ibu untuk meningkatkan pengetahuan dan ketrampilannya.

Pendidikan kesehatan tentang mobilisasi dini bagi ibu postpartum dapat memberikan pengetahuan lebih tentang kesehatan kepada ibu ataupun kepada keluarga agar dapat mengatasi masalah dan mempercepat proses penyembuhan pasca bersalin. Hal ini di karena tahap postpartum merupakan salah satu tahap yang rentan terhadap kejadian perdarahan dan infeksi pada ibu, dan menjadi penyebab terjadinya kematian pada ibu.

Pendidikan kesehatan tentang mobilisasi dini pasca bersalin selain membantu mempercepat penyembuhan juga berfungsi untuk meningkatkan kepercayaan diri dan semangat untuk segera memberikan ASI pada bayinya (Rofiqoch, 2020). sejalan dengan penelitian oleh yang dilakukan oleh Diyah menyatakan bahwa Pendidikan Kesehatan mempengaruhi persepsi ibu post partum dan keluarga tentang perawatan dirii post partum yang dilakukan di Rumah Sakit dr. Soebandi dan di didaerah Puskesmas Kaliwates Jember (Indriyani, 2015).

Hal ini mendorong kami untuk melakukan pengabdian pada masyarakat pemberian edukasi tentang pentingnya mobilisasi dini pada ibu post partum di kelas ibu hamil desa Pamijen Kecamatan Sokaraja Kabupaten Banyumas sehingga para ibu hamil dapat mempersiapkan diri dalam menghadapi proses penyembuhan pasca bersalin dan dapat menurunkan angka kejadian infeksi pasca bersalin.

\section{Metode}

Pelaksanaan pengabdian pada masyarakat (IbM) dilakuan dengan metode learning by doing (belajar dengan mempraktekkan). Transfer IPTEK dilakukan melalui penyuluhan, pelatihan dan praktek mobilisasi dini. Tahap-tahap kegiatan yang dilaksanakan dalam program IbM ini adalah :1) Persiapan program IbM, meliputi survey ke kelompok sasaran, koordinasi dan pengurusan ijin dengan instansi terkait (Pemerintah, Desa, Kecamatam), serta persiapan bahan dan peralatan untuk melaksanakan IbM. 2) Pelatihan kader aisyiyah dan ibu reproduktif. 3) Follow up pada kegiatan pembekalan kader 'Aisyiyah selanjutnya.

\section{Hasil dan Pembahasan}

Kegiatan IbM yang telah dilaksanakan pada kelas ibu hamil Desa Pamijen Kecamatan Sokaraja Kabupaten Banyumas pada tanggal 6 Februari 2020 yang bertempat di Pos Kesehatan Desa (PKD) Desa Pamijen Kecamatan Sokaraja Kabupaten Banyumas dengan jumlah peserta 9 orang. Para peserta yang rata-rata adalah ibu-ibu hamil ini sangat antusias dalam mengikuti kegiatan IbM yang berjudul Pendidikan Kesehatan tentang Mobilisasi Dini Pasca Bersalin.

Para peserta yang terdiri dari ibu hamil memiliki latar belakang pendidikan yang bervariasi dari yang tamat sekolah menengah pertama (SMP) dengan jumlah 1 orang, SMA 7 orang dan tamatan perguruan tinggi 1 orang sampai dengan perguruan tinggi. Para peserta juga merupakan ibu yang sedang hamil TM 3 atau usia kehamilan berkisar 7-9 bulan.

Pelatihan dilakukan pre test untuk mengetahui seberapa tahunya para peserta tentang mobilisai dini pasca bersalin, setelah dilakukan pre test dan hasilnya para peserta sebagian besar 
masih belum mengetahui tentang mobilisasi dini pasca bersalin meskipun sebenarnya ha ini mereka sering melakukan atau mendengar dari para orang tua atau teman-teman yang sudah pernah bersalin.

Diagram dibawah ini merupakan hasil pre dan post test tentang pengetahuan para ibu hamil mengenai pengetahuan para ibu hamil tentang mobilisasi dini pasca bersalin.

Diagram 5.1 Hasil Pre test dan Post tes

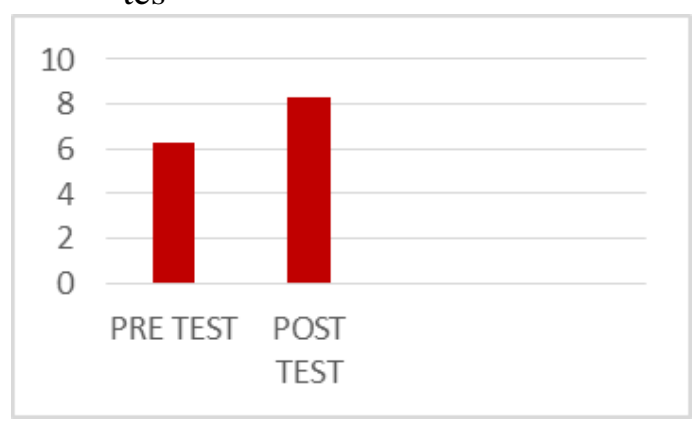

Berdasarkan hasil diatas menunjukkan adanya peningkatan pencapaian skor dalam menjawab soal. Pada awal pelaksanaan pemberian pengetahuan tentang mobilisasi dini pasca bersalin ada seorang ibu yang mendapatkan skor 3 karena hanya mampu menjawab tiga buah pertanyaan dan setelah diberikan edukasi tentang mobilisasi dini pasca bersalin saat kemudian dilakukan post tes ibu tersebut dapat menjawab pertanyaan dengan jawaban benar sebanyak 7 soal atau memiliki skor 7,0. sehingga terdapat peningkatan pengetahuan sebelum dan setelah dilakukan pemberian pendidikan kesehatan tentang mobilisasi dini pasca bersalin.

Secara umum dapat dikatakan bahwa terdapat kenaikan antara nilai pre test dan post tes sebesar $32 \%$ hal ini dapat dihitung dengan jalan membandingkan antara nilai rata rata pre tes sebesar 6,30 dan hasil post tes sebesar 8,30. Hal ini sesuai dengan pendapat Notoatmodjo, 2012 semakin banyak informasi yang diperoleh maka semakin tinggi pula nilai pengetahuannya. Sejalan dengan hasil penelitian tersebut bahwa konseling tentang kesehatan lingkungan mampu meningkatkan pengetahuan, sikap dan perilaku masyarakat di Puskesmas I dan Puskesmas II Baturraden. (Gamelia, 2020).

Pendidikan kesehatan tentang mobilisasi dini pasca bersalin sangatlah penting diberikan kepada ibu hamil terutama ibu hamil TM 3. Dalam kegiatan IbM ini para peserta adalah ibu hamil yang merupakan sasaran tepat karena ibu hamil ini akan menghadapi persalinan, sehingga pemberian informasi tentang mobilisasi dini pasca bersalin sangat membantu para ibu hamil dalam menghadapi persalinan dan nifas sehingga para ibu nantinya akan mempercepat pemulihan luka pasca bersalin baik yang persalinannya normal maupun SC, dikarenakan mobilisasi dini post partum memiliki banyak keuntungan yaitu: Ibu merasa lebih sehat dan kuat, Fungsi usus, sirkulasi, paru-paru dan perkemihan lebih baik, Memungkinkan untuk mengajarkan perawatan bayi pada ibu, Mencegah trombosis pada pembuluh tungkai, Sesuai dengan keadaan indonesia, sosial ekonomis.

Berdasarkan hasil diatas peningkatan pengetahuan masyarakat melalui kegiatan pendidikan kesehatan tentang mobilisasi dini pasca bersalin terdapat peningkatan pengetahuan yang signifikan. Pengetahuan tentang mobilisasi dini pasca bersalin diberikan secara dini kepada ibu hamil bertujuan agar para ibu hamil dapat mempersiapan diri untuk melakukan mobilisasi dini pasca bersalin secara dini karena diharapkan dengan melakukan mobilisasi secara dini pasca bersalin ibu 
yang post partum dapat langsung mempraktikan dan membantu penyembuhan luka uterus dan jalan lahir pasca bersalin. Hal ini sejalan dengan Sianipar (2019) yang menyatakan bahwa mobilisasi atau pergerakan sesegera mungkin bisa mencegah aliran darah terhambat, mobilisasi ini dilakukan setelah 2 jam postpartum. Setelah melakukan mobilisasi maka pengeluaran lochea akan lancar, sehingga pembuluh - pembuluh darah yang ada di otot - otot uterus akan terjepit. Pernyataan tersebut juga sejalan dengan pernyataan dari Rofiqoch (2019) yang menyebutkan bahwa Pelaksanaan pemberian pendidikan kesehatan tentang mobilisasi dini sebaiknya di lakukan sebelum proses persalianan atau pada saat ibu melakukan kunjungan ANC atau kelas ibu hamil. Hal ini bertujuan agar ibu dapat mempersiapkan diri dan keluarga untuk membantu pada saat melakukan mobilisasi setelah bersalin.

\section{Kesimpulan}

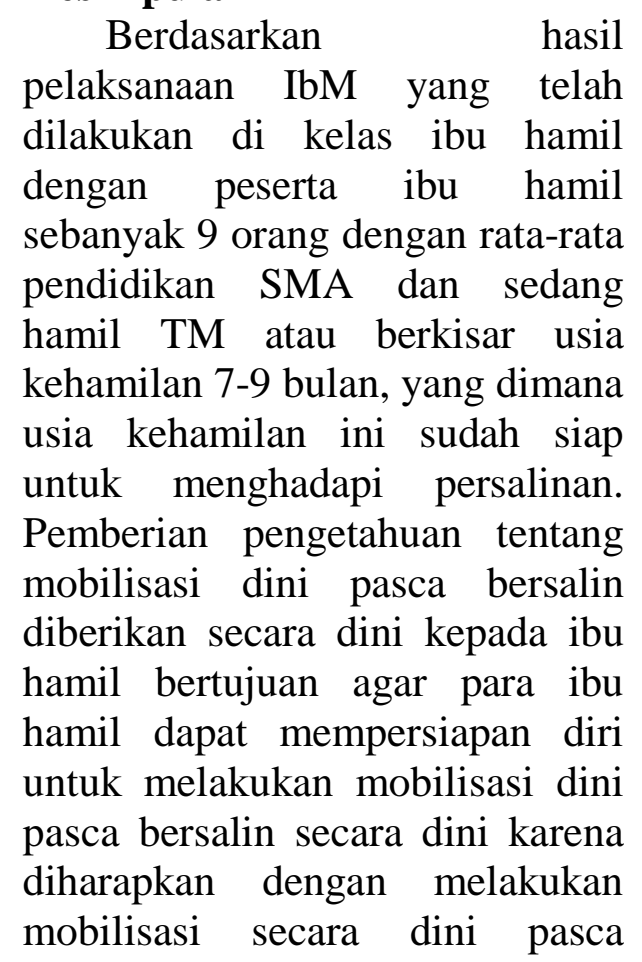

bersalin ibu yang post partum dapat langsung mempraktikan dan membantu penyembuhan luka uterus dan jalan lahir pasca bersalin.

\section{Daftar Pustaka}

$\begin{array}{llr}\text { [1] Rofiqoch, I. } & \text { Pelaksanaan } \\ \text { Pendidikan Kesehatan Mobilisasi } \\ \text { Dini Oleh Bidan Di } & \text { Wilayah } \\ \text { Kabupaten Banyumas. } & \text { Jurnal } \\ \text { Ilmiah Medsains Vol } 5 & \text { No } 02 \\ \text { Tahun } & \text { 2019. } & \text { [Online]. }\end{array}$ https://jurnal.polibara.ac.id/index.p hp/medsains/article/view/91/72. 2019.

[2] Indriyani, Diyah. An Implementation Of Postnatal Education Toward The Perception About Self Care On Immediately And Early Postpartum Period Of Postpartum Mothers And Their Families In Jember. Journal of Nursing and Health Science (IOSR-JNHS) e-ISSN: 2320-1959.p- ISSN: 2320-1940 Volume 4, Issue 5 Ver. V (Sep. Oct. 2015), pp.20-26 www.iosrjournals.org. 2015.

[3] Gamelia, Elviera. DKK. Counseling Effect On The Improvement Of Knowledge, Attitude, And Behavior Of Public Health Environment. Jurnal Kesmasindo, Volume 7, Nomor 3, Juli 2015, pp.218-224. 2015.

[4] Notoatmodjo S. Promosi Kesehatan dan Perilaku Kesehatan. Jakarta: PT Rineka Cipta. 2012.

[5] Sianipar, Kandace. Hubungan Mobilisasi Dini Pada Masa Nifas Dengan Pengeluaran Lochea Di Praktek Mandiri Bidan Bidan L.M Pematangsiantar. Jurnal Ilmiah PANNMED. Vol. 14 No.01 Mei-Agustus 2019. [Online]. Http:/Users/ACER/Downloads/572 -Article\%20Text-844-1-10-201911 01.pdf. 2019. 